\title{
TO STUDY PORT SITE INFECTIONS (PSI) FOLLOWING LAPAROSCOPIC CHOLECYSTECTOMY AND TO MINIMIZE MORBIDITY
}

\author{
Raj Rishi Sharma1, Anil Mehta², Rachna Magotra³, Arihant Sharma ${ }^{4}$
}

${ }^{1}$ Senior Consultant, Department of Surgery, J\&K Health Services, Jammu and Kashmir, India.

${ }^{2}$ Consultant, Department of Obstetrics and Gynaecology, J\&K Health Services, Jammu and Kashmir, India.

${ }_{3}^{3}$ Associate Professor, Department of Anatomy, GMC, Jammu, Jammu and Kashmir, India.

4Intern, Department of Surgery, GMC, Jammu, Jammu and Kashmir, India.

\section{BACKGROUND}

ABSTRACT

Laparoscopic cholecystectomy is the gold standard treatment for symptomatic gall stones.(1) Port site infection(PSI) is a common complication of laparoscopic cholecystectomy which often proves problematic and nagging for the patient and the operating surgeon; the former being affected by increased morbidity in terms of pain, suboptimal level of wellbeing, increased hospital stay, emotional turmoil, and increased economic loss.

\section{MATERIALS AND METHODS}

The present study was a prospective observational study conducted on 620 patients who underwent laparoscopic cholecystectomy in Government Hospital, Sarwal, between February 2014 to January 2018. This involves the study of infection of port site following lap cholecystectomy over a period of four years and aims to minimise the incidence of PSI which is showing a latest trend from polymicrobial to atypical form. Out of 620 patients, 600 patients were operated with 3 ports and 20 patients with 4 ports.

\section{RESULTS}

PSI was determined to be $4.67 \%$ and was most commonly due to Staphylococcus aureus though atypical microorganisms were the causative agents in some cases. The commonest site of post-surgical infection was the epigastric port.

\section{CONCLUSION}

PSI is a commonly observed complication following laparoscopic cholecystectomy. With the passage of time, common pyogenic organisms are being replaced by atypical organisms.

\section{KEY WORDS}

Laparoscopic Cholecystectomy, Port Site, Complication, Morbidity, Atypical Bacteria.

HOW TO CITE THIS ARTICLE: Sharma RR, Mehta A, Magotra R, et al. To study port site infections (PSI) following laparoscopic cholecystectomy and to minimize morbidity. J. Evolution Med. Dent. Sci. 2018;7(52):5513-5515, DOI: 10.14260/jemds/2018/1220

\section{BACKGROUND}

Laparoscopic cholecystectomy is the gold standard treatment for symptomatic gall stones.(1) Port site infection(PSI) is a common complication of laparoscopic cholecystectomy which often proves problematic and nagging for the patient and the operating surgeon; the former being affected by increased morbidity in terms of pain, suboptimal level of wellbeing, increased hospital stay, emotional turmoil, and increased economic loss. PSI may decrease the sense of accomplishment of the surgeon, after surgery and in addition, may invite allegations, against his sterilization and operative expertise. Now a days, there is a changing pattern of infection from microbial pyogenic organisms to polymicrobial and atypical mycobacteria which has led to failure of PSI to respond to standard antimicrobial agents. Moreover, the inappropriate use of antibiotics has led to the emergence of resistant microorganisms. (2)

'Financial or Other Competing Interest': None.

Submission 04-11-2018, Peer Review 06-12-2018,

Acceptance 12-12-2018, Published 24-12-2018.

Corresponding Author:

Dr. Anil Mehta,

R/o. 681, B/K Last Morh,

Gandhinagar, Jammu-180004,

Jammu and Kashmir, India.

E-mail: beluanil@gmail.com

DOI: $10.14260 /$ jemds $/ 2018 / 1220$

\section{(c) (i) $\odot$}

The aim of this study is to study the changing pattern of PSI following laparoscopic cholecystectomy, so as to decrease the morbidity of the patients. The prolonged healing course after surgery, emphasizes the importance of premonitive awareness of this difficult but preventive scenario.

\section{Aim of the Study laparoscopic cholecystectomy. \\ Study Design \\ Cohort Prospective Observational Study.}

To study changing trend of Port Site Infection (PSI) following

\section{MATERIALS AND METHODS}

The present study was Prospective observational study conducted in Government Hospital, Sarwal, from February 2014 to January 2018 (48 months). Out of total 700 patients who underwent laparoscopic cholecystectomy, only 620 were included in our study. Out of them 496 were females and 124 were males (Table I). In 600 cases, the surgery was done with three ports and in 20 cases the fourth port was introduced. The patient who had to be converted to open cholecystectomy peroperatively or those having some chronic illness were excluded from this study.

All patients were asked to take a bath preoperatively using an antiseptic soap and the abdomen was prepared for surgery. A shot of prophylactic antibiotic (Inj. Ceftriaxone 1 gm.) was given to all the patients one hour prior to surgery. 
During the surgery, the gall bladder was removed through the epigastric port. The requirement of fourth port was more in males. It was needed in 20 patients in our study. The total incidence of PSI was $4.67 \%$ and was most commonly seen at the epigastric port. (Table-2)

The dressing was changed after $24 \mathrm{hrs}$ and stitches were removed on $8^{\text {th }}$ post-operative day. In cases with any sign of infection, the culture was taken from the wound and sent for microbiological examination and the treatment was started as per the report of the culture.

Incidence of infection was more with prolonged procedure, increasing age of the patient, male sex and any coexisting disease.

The treatment of the wound depends on the type of microorganisms present in the culture. The laparoscopic instrument used during the study were sterilised by $2 \%$ glutaraldehyde solution with a contact time of 20 minutes before surgery and were washed with warm saline before use.

\section{RESULTS}

In the present study, out of 620 patients only 29 cases had port site infection so the incidence of PSI in this study was 4.67\%. Amongst 620 patients studied 496 were females and 124 were males. The PSI was seen in 19 out of total 124 cases in males and in 10 out of total 496 cases in females. Therefore, the PSI was $15.32 \%$ in males and $2.01 \%$ in females. Surgery was done using three ports in 600 patients and only in 20 patients fourth port was used. PSI was seen in 24 cases out of total 29 at the epigastric port and only in 5 cases it was seen at the umbilical port. The infection was mainly superficial.

Organisms detected after microbiological examination of culture were as follows

1. Staphylococcus aureus, 11

2. Pseudomonas, 1

3. Klebsiella, ${ }^{2}$

4. Actinobacter, 3

5. Escherichia coli, 1

6. Enterobacter faecalis, ${ }^{2}$

7. Bacteroides fragilis, ${ }^{1}$

8. Mycobacterium fortuitum, ${ }^{2}$

9. Mycobacterium cheloneae, ${ }^{4}$

10. Mycobacterium abscessus, ${ }^{2}$

\begin{tabular}{|c|c|c|c|}
\hline Gender & $\begin{array}{c}\text { Total No. of } \\
\text { Cases }\end{array}$ & $\begin{array}{c}\text { Total No. of } \\
\text { Cases Infected }\end{array}$ & Percentage \\
\hline Male & 124 & 19 & 15.32 \\
\hline Female & 496 & 10 & 2.01 \\
\hline Total & $\mathbf{6 2 0}$ & $\mathbf{2 9}$ & $\mathbf{4 . 6 7}$ \\
\hline \multicolumn{4}{|c|}{ Table 1 } \\
\hline
\end{tabular}

\begin{tabular}{|c|c|}
\hline Site of Port & Incidence of PSI \% \\
\hline Umbilical port & $0.80 \%$ \\
\hline Epigastric port & $3.87 \%$ \\
\hline $3^{\text {rd }}$ port & $0 \%$ \\
\hline $4^{\text {th }}$ port & $0 \%$ \\
\hline \multicolumn{2}{|c|}{ Table 2 } \\
\hline
\end{tabular}

\begin{tabular}{|c|c|}
\hline Name of Study & Incidence of PSI (\%) \\
\hline Mir et al & 6.7 \\
\hline Shindholimath et al & 6.3 \\
\hline S.S Kumar et al & 5.7 \\
\hline Den Hoed et al & 5.3 \\
\hline Muhammad Naeem Taj & 5.48 \\
Mumtaz KH Al Naser & 4.5 \\
\hline \multicolumn{2}{|c|}{ Table 3 } \\
\hline Present Study \\
\hline
\end{tabular}

\section{DISCUSSION}

All surgeries have an inherent risk of infection, but the risk is relatively less in case of laparoscopic or minimal access surgery. PSI, a preventable entity, has become a sore eye of the minimal access surgeon. Though infrequent, its occurrence can damage the reputation of the surgeon and can frustrate the patient. The emerging and rapidly changing bacterial flora is posing a real challenge to the treating surgeon. This study is likely to help the training surgeon to be aware of this complication while treating PSI so that proper treatment can be instituted at the earliest. Also, proper preoperative steps should be taken to prevent this complication to settle in. Many authors have studied the PSI after laparoscopy as shown in table- 3 .

Most of the authors like Mir et al,(3) Shindholimath et al,(4) S. S. Kumar et al, (5)Den Hoed et al(6) and Muhammad Naeem $\mathrm{Taj}^{(7)}$ were of the opinion that the incidence of PSI is more than $5 \%$ but in our study it was less than $5 \%(4.67 \%)$. However some authors Like Coliza et al(8) have reported the incidence of PSI to be less than $2 \%$. The present study is in accordance with study of Mumtaz KH Al-Naser 2017(9) where the incidence of PSI was $4.5 \%$. High level of disinfection can decrease the incidence of PSI that is the laparoscopic instrument should be dismantled and cleaned completely.(10) However atypical microorganism show resistance to routinely used disinfectants. Incidence of PSI in present study was more at epigastric port which is in accordance with authors like Mumtaz KH Al-Naser.(9) This was not in accordance to Dr SS Kumar(5) and Muhammad Naeem Taj(7) where incidence was more at the umbilical cord. The port from where the gall bladder was extracted was most susceptible to infection, which was the epigastric port, in the present study. Similar observations were observed by $\mathrm{Dr}$ Narayan Das et al 2016.(11)

As discussed by Richards $\mathrm{C}$ et $\mathrm{al},(12)$, the ten commandments to prevent PSI are

1. Use of disposable trocars and instruments and adequate availability of properly sterilized reusable trocars to cover all the surgical procedures in a day.

2. Use of autoclavable laparoscopic hand instruments.

3. Use of instruments with good ergonomics, limited joints and facility for proper cleaning of the debris collected in its crevices.

4. A proper cleaning of the instruments is best achieved by ultrasonic technology, use of autoclaved water for cleaning the instruments after dismantling.

5. Proper guidelines should be followed regarding the concentration, contact time and cycles of use for instruments sterilization with liquid sterilizing agents.

6. Use of plasma sterilizer or ethylene oxide in between the consecutive surgery for instrument sterilization. 
7. Avoiding inter-departmental sharing of instruments such as using instruments for gynaecological or urological procedures.

8. Avoiding spillage of bile or gut contents in the operative area or the port site.

9. Use of non-porous specimen retrieval bags for retrieving the specimens.

10. Thorough irrigation and cleaning of the port site before closure.

\section{CONCLUSION}

Prevention is better than cure. PSI is a common but preventable complication after laparoscopic cholecystectomy as everything comes with a price tag. Its incidence can be decreased by proper sterilization of instruments. The infection is mostly superficial and seen at the site, from where the gall bladder is extracted. The infection is more common in males. The polymicrobial infection and infection caused by atypical mycobacterium have prolonged morbidity. Therefore, culture and determination of sensitivity to antimicrobials are important as such infections respond to macrolides, quinolones and aminoglycosides and not to standard antimicrobials. More research is needed to diagnose and treat this problem with proper notification of cause, incidence and antimicrobial sensitivity of port site infections following laparoscopic cholecystectomy.

\section{REFERENCES}

[1] Mehraj A, Naqvi MA, Feroz SH, et al. Laparoscopic cholecystectomy: an audit of 500 patients. Journal of Ayub Medical College Abbotabad 2011;23(4):88-90.

[2] Iqbal MZ. Incidence of postsurgical infections in orthopaedics (dissernation) Karachi, Pakistan. Journal of College of Physicians and Surgeons of Pakistan 1997.
[3] Mir IS, Ahmad M, Ahad B. Establishing pneumoperitoneum safely for laparoscopic surgeries. JK-Practitioner 2005;12(4):224-6.

[4] Shindholimeth VV, Seenu V, Parshad R, et al. Factors influencing wound infection following laparoscopic chloecystectomy. Trop Gastroenterology: Official Journal of the Digestive Diseases Foundation 2003;24(2):90-2.

[5] Sathesh-Kumar T, Saklani A, Vinayagam R, et al. Spilled gallstones during laproscopic cholecystectomy: a review of the literature. Postgraduate Medical Journal 2004;80(940):77-9.

[6] Den Hoed PT, Boelhouwer RU, Veen HF, et al. Infections and bacteriological data after laparoscopic and open gall bladder surgery. J Hosp Infect 1998;39(1):27-37.

[7] Taj MN, Iqbal Y, Akbar Z. Frequency and prevention of laparoscopic port site infection. J Ayub Med Coll Abbottabad 2012;24(3-4):197-9.

[8] Colizza S, Rossi S, Picardi B, et al. Surgical infection after laoroscopic cholecystectomy: ceftriaxone versus ceftazidime antibiotic prophylaxis. A prospective study. Chir Ital 2004;56(3):397-402.

[9] Al-Naser MKH. Port site infections after laproscopic cholecystectomy. International Journal of Medical Research and Health Sciences 2017;6(6):132-7.

[10] Rodringues C, Mehta A, Jha U, et al. Nosocomial Mycobacterium chelonae infection in laparoscopy. Infect Control Hosp Epidemiology 2001;22(8):474-5.

[11] Narayan D, Anarsh D, Anup KS. A study of port site infection following laparoscopic cholecystectomy in a teaching hospital. IOSR-JDMS 2016;15(9):61-3.

[12] Richards C, Edwards J, Culver D, et al. Does using a laproscopic approach to cholecystectomy decrease the risk of surgical site infection? Ann Surg 2003;237(3):358-62. 